\title{
A política da má vontade na implantação das cotas étnico-raciais
}

DoI

http://dx.doi.org/10.11606/ 2179-0892.ra.2017.132062

\section{Marcio Goldman e Gabriel Banaggia}

- Museu Nacional/UFR] / Rio de Janeiro, RJ, Brasil

$\checkmark$ marcio.goldman@gmail.com,gbanaggia@gmail.com

\section{RESUMO}

A primeira parte deste texto elabora reflexões sobre racismo e inclusão que derivam do cruzamento de nossa formação como antropólogos e de nossa experiência como etnógrafos que acreditam que os efeitos do trabalho de campo e da etnografia devem ultrapassar em muito e em todas as direções o campo teórico ou acadêmico, já que há sempre algo a

Ações afirmativas, Inclusão, Racismo, Pós-graduação, Antropologia social. aprender com as pessoas com quem trabalhamos. Em seguida é apresentado um relato do longo processo de implantação das cotas étnico-raciais no Programa de Pós-Graduação em Antropologia Social do Museu Nacional. Além de sua importância intrínseca, acreditamos que esse registro pode ser útil para o crescente número de iniciativas que visam implementar políticas de ação afirmativa em diversos programas de pós-graduação. Ao mesmo tempo, não nos furtaremos a algumas primeiras avaliações do funcionamento e dos rumos que o processo vem tomando no PPCAS do Museu Nacional, bem como a propor algumas conexões entre essa experiência e as reflexões da primeira parte do texto. 
Este texto trata de um tema no qual não somos exatamente "especialistas", já que ambos pesquisamos religiões de matriz africana no Brasil. Se é verdade, em função disso, que algumas das reflexões que aqui avançamos possuem um estilo algo impressionista e são marcadas por um tom talvez excessivamente vivido, elas não visam fornecer nenhum tipo de crítica de caráter ideológico ou mesmo pessoal. Essa não é, de modo algum, nossa intenção, e o que pretendemos fazer, como bons antropólogos que gostaríamos de ser, é tentar extrair de experiências muito concretas reflexões que ajudem a tornar inteligíveis outras situações igualmente concretas.

Por outro lado, vale a pena observar que em um mundo perfeito o tema das ações afirmativas e das cotas étnico-raciais certamente não teria nenhuma necessidade de "especialistas". Afinal, como escreveu Immanuel Kant em um de seus raros momentos de lucidez política, precisamos sempre colocar a questão de se realmente desejamos "que o conhecimento que diz respeito a todos os seres humanos ultrapasse o entendimento comum e seja revelado (...) somente por filósofos" (citado por Needham, 1972: 13) — ou por "cientistas", poderíamos hoje acrescentar.

Como se sabe, foi o brutal corte de $75 \%$ nas verbas de custeio da pós-graduação brasileira que levou o PPCAS a procurar ajuda da Fundação Ford. E ainda que dessa parceria muitas coisas importantes tenham surgido, começando por este seminário, não podemos deixar de assinalar que ele se realizou no contexto do que consideramos a mais grave ameaça de destruição do sistema brasileiro de pós-graduação - e talvez do ensino público superior em geral —em marcha no país desde há muito tempo. O próprio seminário ocorreu em um Dia Nacional de Paralisação do Serviço Público, convocado pelo Fórum das Entidades Nacionais dos Servidores Públicos Federais como forma de luta e protesto contra o que está acontecendo sob nossos olhos. As alternativas são claras: não fazer nada, salvar a própria pele ou buscar reverter a situação.

O que tentaremos fazer aqui é, primeiro, apresentar algumas reflexões que derivam do cruzamento de nossa formação como antropólogos e de nossa experiência como etnógrafos. Ou, para ser mais precisos, de antropólogos que acreditam que os efeitos do trabalho de campo e da etnografia devem ultrapassar em muito e em todas as direções o campo teórico ou acadêmico na medida em que há sempre algo a aprender com as pessoas com quem trabalhamos. A inclusão das ontologias e das epistemologias que essas pessoas nos ensinam nos parece um passo preliminar crucial em qualquer projeto sério de inclusão. Esta é, nos parece, a única forma da antropologia contribuir para esse processo sem trair o que ela tem de melhor e, consequentemente, sua forma mais eficaz de contribuição.

Depois disso, apresentaremos um relato do longo processo de implantação 
das cotas étnico-raciais no PPGAS do Museu Nacional. Além de sua importância intrínseca, acreditamos que essa apresentação pode ser útil para o crescente número de iniciativas visando a implementação de políticas de ação afirmativa em diversos programas de pós-graduação. Ao mesmo tempo, não nos furtaremos a algumas primeiras avaliações do funcionamento e dos rumos que o processo vem tomando no PPGAS. Desnecessário dizer que essa avaliação é exclusivamente dos autores deste texto, que assumimos inteira responsabilidade por ela, e que ela visa exclusivamente o aprimoramento dos mecanismos implementados.

Começamos, então, evocando um episódio ocorrido logo no início do trabalho de campo de um de nós, em Ilhéus, na Bahia, durante as comemorações do Dia da Consciência Negra de 1998, organizadas pelo Conselho de Entidades Afro-Culturais de Ilhéus. Nessa ocasião, um militante negro muito articulado com o prefeito da cidade organizou um evento, a ser realizado no dia 19 de novembro como parte das comemorações do Dia de Zumbi, como a data era mais conhecida por lá nessa época. Fracassadas as tentativas de trazer convidados "de fora” - uma vez que a Prefeitura se recusara a arcar com as despesas necessárias —, foi organizada uma mesa-redonda da qual participaram esse mesmo militante, um representante do Movimento Negro Unificado local, um representante do que era chamado na época "movimento cultural negro de Ilhéus", o coronel comandante do Tiro de Guerra local, um membro de um grupo de capoeira e aquele que foi apresentado como "o antropólogo que pesquisa há muito tempo a cultura negra de Ilhéus", "professor da UFR]", Marcio Coldman.

Tanto o militante do MNU quanto o antropólogo insistiram nas questões ligadas ao racismo; o coronel (que com o antropólogo completava os dois únicos brancos em meio a um público de pouco mais de 50 pessoas) tratou de negar a existência de qualquer tipo de discriminação racial no Brasil. E, enquanto o militante do MNU chamava a atenção para o risco representado pelo argumento de uma matéria publicada na Veja já naquela época intitulada "a ciência prova a inexistência das raças", o coronel proclamava que pelo menos no Exército brasileiro "só há uma raça, a raça brasileira".

Os discursos do organizador do evento e do representante do grupo de capoeira foram algo diferentes. Sem negar a existência de racismo, insistiam na importância da iniciativa individual, de "correr atrás", como se costuma dizer na região, de ser bem-sucedido pessoalmente, servindo, assim, como exemplo para os demais ao incentivar sua "autoestima". Contestado por uma militante presente - que indagou se o discurso da "falta de autoestima" não seria um modo de culpabilizar os próprios negros por sua discriminação - , ele respondeu que desejava apenas chamar a atenção para a importância de se enfatizar "os progressos feitos pelo negro", o que não deixava de ser uma forma de articular grandes 
questões coletivas com experiências, interesses e ambições pessoais.

O conjunto de acontecimentos e discursos observados em Il héus aponta, claro, para diversas direções (ver Goldman, 2006: 224-225). Trata-se aqui apenas de explorar os efeitos que esse episódio foi tendo sobre um etnógrafo que, na época, não tinha a mesma posição sobre as cotas que tem hoje. Não se trata tampouco de apresentar um desses testemunhos do tipo "eu era cego mas agora posso ver", já que sabemos onde esse tipo de coisa costuma dar. O ponto é que deve ter sido a primeira vez que o antropólogo experimentou pessoalmente esse sentimento que todo cientista social ou natural bem pensante deve sentir quando se dá conta de que uma categoria que acreditava ter ajudado a "desconstruir", provando assim sua boa vontade e a correção de seu alinhamento ético-político, já havia sido apropriada por aqueles contra quem era acionada, que transformaram seu sentido e passaram a usá-la como arma de luta. Esse movimento ilustra um certo modo de funcionamento das formas modernas e contemporâneas de dominação, que não se apoiam apenas na força, mas também, e talvez sobretudo, na verdade. Porque desse ponto de vista, por mais injustiças que se cometa com os outros, elas um dia deverão ser perdoadas uma vez que agora sabemos que estávamos então errados. Porque é sempre possível se arrepender de erros passados quando se os substitui por novas "verdades", que, claro, continuam a orientar nossas ações sem qualquer sentimento de dúvida.

Nesse sentido, queríamos explorar aqui, rapidamente, esses dois aspectos interligados da questão. Primeiro, qual a imagem da ciência subjacente às críticas de base "científica" que costumam ser dirigidas às ações afirmativas e mais particularmente às políticas de cotas raciais? Segundo, qual a política, ou a micropolítica, imanente a essas imagens e a essas críticas?

Sobre a imagem da ciência brandida contra as cotas, o mínimo que se pode dizer é que deriva de uma visão iluminista e positivista da atividade científica há muito deixada de lado na prática efetiva dos cientistas, mas que continua a informar suas tentativas de intervenção no campo político mais amplo. Trata-se de uma forma de tecnocracia, cujas bases epistemológicas, ontológicas e ético-políticas não são difíceis de perceber, ainda que nunca sejam explicitadas. Como escreveu, por exemplo, o geneticista e médico Sérgio Pena (2007: 37), Tales de Mileto fundou "não só a filosofia ocidental, mas também o pensamento científico" ao revelar que "o mundo que percebemos é caracterizado por uma grande diversidade, mas essa diversidade é apenas aparente e por trás dela existe uma unidade fundamental". Que Tales em sua época, acrescenta o autor, tenha acreditado que essa unidade estava na "água" - enquanto hoje sabemos que é no código genético que devemos buscá-la —é, sem dúvida, secundário face à grandeza de sua descoberta.

Em certo sentido, tudo está aqui: a noção de raça é "perigosa" porque "divide" 
uma unidade fundamental, a humanidade (gênero ou raça humana, preferem alguns). Essa ontologia pré-socrática desemboca naturalmente em uma epistemologia realista. Trata-se de saber se "raça" existe ou não existe. Neste ponto, é sempre apresentado ou evocado o testemunho dos biólogos, geneticistas, antropólogos biológicos, que "sabem" que tal coisa não existe. Como escreve, com igual clareza, o mesmo Sérgio Pena: "Certamente, a humanidade do futuro não acreditará em 'raças' mais do que acreditamos hoje em bruxaria” (Pena, 2007: 45).

Mais estranho é que tantos cientistas humanos - acostumados a lidar com a construção social do conhecimento ou com as misturas entre ciências e interesses - tenham aceitado com tanta facilidade essas posições. Não apenas quando evocam os cientistas naturais para garantir "o fato cientificamente comprovado da inexistência das 'raças"” — que deve, então, "ser absorvido pela sociedade e incorporado às suas conviçç̃es e atitudes morais". Mas também quando opõem a verdadeira história da África ou as efetivas características da sociedade brasileira ao que consideram as ilusões dos que não pensam como eles. "Desessencializar" é uma tarefa mais complexa do que se imagina, especialmente quando, via de regra, consiste na substituição das supostas essências das minorias por aquelas da maioria.

Afinal, até outro dia, a noção de raça era "científica" - mesmo alguns cientistas que se posicionaram contra as cotas pensam assim - e em nome dela foram cometidos alguns dos maiores crimes da história. Isso deveria levar a uma certa modéstia e ao reconhecimento de que, se as certezas passadas da ciência eram passageiras, não há por que supor que as atuais sejam definitivas. O que parece certo é que não é apenas em bruxaria ou em raças que "a humanidade do futuro" não acreditará, se ela existir, mas também em genes e em estruturas sociais.

Mesmo hoje, contudo, se adotarmos uma outra imagem da ciência (a de cientistas como Stephen Jay Could ou Ilya Prigogine, ou de filósofos, como Michel Serres, Bruno Latour ou Isabelle Stengers), podemos formular o problema de maneira inteiramente diversa. Não é nada evidente que "raça" seja uma "coisa" cuja existência ou inexistência poderia ser resolvida ou arbitrada pela ciência ou por qualquer tipo de discurso. Trata-se, antes, de uma categoria ou conceito, neste caso um que já foi considerado científico e que agora parece não o ser mais. Como qualquer categoria, serve para agrupar de determinadas maneiras a infinita diversidade da experiência, não para recortar uma unidade fundamental. Esses modos de organização da experiência podem ou não ser considerados satisfatórios, mas isso sempre se dá em determinadas circunstâncias, para determinadas finalidades e por determinados sujeitos. Tal perspectiva poderia, pois, ser chamada de "pragmática", se entendermos o termo no sentido mais nobre que lhe emprestam os filósofos: o de uma arte das consequências, não o de uma questão de princípios. A redução das políticas de combate às 
desigualdades raciais à noção de "políticas raciais" e dos movimentos pela ação afirmativa a "processos de racialização" deixam precisamente de lado esse caráter pragmático, uma vez que essas políticas tentam combater o racismo em um campo que não é apenas o das ideias e preconceitos, mas no da política em geral e no das políticas públicas em particular.

Isso nos coloca na pista da segunda questão, a política ou micropolítica imanente às críticas das cotas raciais. Aqui, tudo se passa como numa antiga anedota judaica contada por Freud. Alguém acusa o vizinho de ter devolvido estragada a chaleira que ele lhe havia emprestado; o vizinho responde que a devolveu em perfeito estado; ela já estava estragada ao ser emprestada; sequer tomou emprestada a chaleira. Freud analisa essa piada a fim de demonstrar certos modos de funcionamento do inconsciente, mas nós acreditamos que ela é uma admirável ilustração de certos modos de pensar que, com Deleuze (1990), chamaríamos "de direita", mais do que "da direita" — o que significa, aliás, que ninguém está livre de neles embarcar.

Assim, ouvimos que "raças não existem"; e também que "há mais negros do que parece em posições de prestígio"; que "não existe problema racial no Brasil"; e também que "as cotas agravam o problema racial". Não se trata, contudo, de simples imprecisão ou falta de lógica. Como escreveu Deleuze "por trás de todo contrassenso há uma política", e a questão é que política está presente aqui. Como adiantamos, pensamos que se trata de uma política "de direita" no sentido também definido por Deleuze: negação da existência do problema; tentativa de interromper os movimentos; reflexão que sempre toma a si mesmo como centro da questão.

Não acreditamos que faz muito sentido discutir a questão metafísica da existência ou inexistência das raças, assim como se alguém é ou não é racista. Por outro lado, acreditamos que não é tão difícil perceber posições, atitudes e políticas que contribuem para a manutenção da discriminação racial ou que a combatem. Por racismo pode-se entender tanto preconceitos, mais ou menos pessoais, quanto fatos relativamente mensuráveis. No primeiro caso, nunca podemos ter certeza de nada, já que a interioridade última das pessoas é inescrutável. No segundo, e ainda que índices possam sempre ser interpretados de muitas formas, somos ao menos capazes de nos colocar na pista do problema: que o racismo, mais ou menos que um preconceito ou uma ideologia, é sobretudo uma prática e, mais precisamente, uma forma de exercício de poder.

Essa confusão entre preconceito e prática, ideologia e poder, pode, talvez, explicar o que a antropóloga Ana Lúcia Valente (2006) chamou, já há mais de dez anos, de "má vontade antropológica" para com as cotas para negros nas universidades, em um importante e quase desconhecido artigo que tem como subtítulo "usos e abusos da antropologia na pesquisa educacional: quando os antropó- 
logos desaprendem". Valente define essa má vontade como uma "disposição desfavorável", uma "prevenção", que dificilmente oculta a "vaidade, presunção, desinteresse, indiferença, desconhecimento, omissão..." que, sabemos, podem povoar o mundo acadêmico.

Se abstrairmos possíveis razões de ordem pessoal, não parece muito difícil perceber que as dificuldades da antropologia, em especial a brasileira, frente a situações como essas derivam, ao menos em parte, de uma característica bem conhecida da disciplina no país. A saber, seu envolvimento, desde o início, com o chamado processo de construção da nação. O problema é que, como todos sabemos, essa construção da nação sempre se dá, de forma mais ou menos violenta, contra tudo e todos os que pretendam afirmar suas singularidades. E é por isso aliás que os críticos das ações afirmativas parecem acreditar que a única forma de identidade efetivamente legítima é a "identidade nacional", todas as demais sendo consideradas "divisões perigosas".

É sem dúvida verdadeiro que o uso político da noção de identidade está ligado a um deslocamento no caráter das exigências apresentadas por certos grupos sociais principalmente a partir da década de 1960. Em lugar da simples extensão de direitos supostamente universais em nome de uma "igualdade" abstrata, mulheres, negros, índios, homossexuais, deficientes etc., passaram a reivindicar direitos específicos e, por definição, não universalizáveis. Sobre todas essas especificidades sempre pairou, contudo, a sombra de uma espécie de direito de ordem superior, que se converteu em algo como uma palavra de ordem: o direito à diferença. Por um lado, não há dúvida de que esse tipo de direito sempre foi de difícil codificação e assimilação tanto pelo direito burguês quanto pelas reivindicações do proletariado. Por outro, contudo, hoje parece legítimo indagar se, formulado desse modo abstrato, ele não acabou funcionando também como um dispositivo que, capturando a irredutível especificidade de reivindicações muito heterogêneas, ajudou a esvaziar de toda a sua aspereza as diferenças que então se apresentavam, reconduzindo-as a um direito genérico mais de acordo com as formas jurídicas e políticas clássicas. Ou seja, é o caso de se perguntar se essa palavra de ordem não acabou fazendo com que, para usar as palavras da escritora ganense Ama Ata Aidoo (1977: 29), "a gente nem possa curtir nossas Diferenças em paz".

Dizíamos acima que a inclusão de epistemologias e ontologias outras nos parece parte inextrincável de qualquer processo de inclusão, ao obrigar a universidade a se transformar na medida em que se abre para os portadores desses saberes - e não a permanecer magnanimamente a mesma, na medida em que "aceita os excluídos" e trata rapidamente de convertê-los aos valores dominantes. Isso significa que é preciso renunciar completamente às concepções liberais e paternalistas das ações afirmativas, que as encaram como concessões aos 
"desfavorecidos" e que muitas vezes perguntam "por que os negros e indígenas, e não os palestinos e caboclos"? Ou àquelas que tentam limitar o direito dos novos estudantes a suas relações com sua própria "comunidade": indígenas estudando indígenas, negros estudando negros, e brancos estudando todo mundo... As ações afirmativas e as cotas étnico-raciais são políticas, no sentido forte e nobre da palavra definido por Philippe Pignarre e Isabelle Stengers (2005: 25-26): "Essas práticas que se aplicam a situações que dividem e fazem hesitar". Elas são o resultado atual e talvez provisório de reivindicações e lutas seculares em relação às quais nossa escolha é muito simples: deixaremos que fracassem, tentaremos destruí-las ou nos aliaremos a elas?

Foi exatamente nesse sentido que, mais de dez anos atrás, um grupo de estudantes do PPGAS do Museu Nacional se dispôs a pensar e elaborar uma proposta de ação afirmativa para ingresso no Programa. Um de nós, Gabriel Banaggia, participou diretamente desse coletivo, mas acreditamos que a exposição que segue - revisada por alguns outros participantes — não traduz apenas opiniões pessoais, mas um tipo de agenciamento coletivo de enunciação que se deu na época e, de algum modo, prossegue até hoje. Além, claro, de ser uma espécie de descrição quase etnográfica de processos que remetem a eventos históricos e políticos de alcance mais amplo.

Lembremos que em 2006 surgiram na esfera pública dois abaixo-assinados a respeito de um par de propostas de lei então em discussão (a Lei de Cotas e o Estatuto da Igualdade Racial). A presença de nomes de professores do PPGAS do Museu Nacional nos dois manifestos chamou a atenção dos alunos para a inevitável proximidade de nossa comunidade desse debate. O número de professores signatários do documento favorável às iniciativas era bem maior que o daqueles que assinaram o documento contrário a elas (nove a dois), o que sugeria que um debate que inicialmente parecia ser muito polarizado revelava, na verdade, o que muitos já intuíam: nem sempre as vozes que mais recebiam espaço nos grandes meios de comunicação eram representativas de posições majoritárias na própria academia (sobre todo esse debate, ver: Carvalho, 2006; Carvalho e Segato, 2002; Feres Jr., 2004; Feres Jr. e Daflon, 2007; Silvério, 2002; Vários Autores, 2005).

Foi nesse contexto que José Jorge de Carvalho, da Universidade de Brasília, foi convidado a falar do tema em uma das palestras do PPCAS. A palestra, intitulada "O confinamento racial do mundo acadêmico brasileiro", foi proferida para uma sala abarrotada, com alunos no chão, e consistiu num diagnóstico detaIhado de algo que a própria composição da audiência revelava: a universidade brasileira, em todos os seus níveis, é muito desproporcionalmente branca.

Provocados pelo palestrante, alguns dos professores presentes arriscaram uma estimativa do número de doutores negros formados pelo PPGAS em seus 
quase 40 anos de existência na época: apenas quatro dos mais de 125 doutores formados até então, sendo que metade deles estrangeiros. Nenhum indígena. Ao final da fala, se não nos falha a memória, uma aluna negra do doutoradoposteriormente professora e à época do seminário no qual este texto foi apresentado, coordenadora do PPCAS - Maria Elvira Diaz Benitez, ainda perguntou a José Jorge o que ele imaginava que poderia ser feito para alterar esse grave quadro que acabara de ser exposto. A resposta foi outra pergunta: "O que vocês, antropólogos alunos do Museu Nacional, podem fazer para mudar esse quadro?".

Ainda em 2006, outro evento contribuiu de modo decisivo para que o tema das ações afirmativas passasse a ocupar um lugar central no PPCAS do Museu Nacional - ao menos entre boa parte de seus alunos. Uma ex-aluna de mestrado, negra, recebeu uma das bolsas do Programa Internacional de Bolsas de Ação Afirmativa da Fundação Ford (o International Fellowship Program, IFP, hoje descontinuado, e que envolvia, como se sabe, um criterioso processo de seleção). Sabendo que um estudante indígena que havia recebido a mesma bolsa fora aceito no mestrado do PPCAS sem necessidade de passar por todo o processo seletivo, ela reivindicou o mesmo tratamento. Uma parte do colegiado do Programa, contudo, considerou que esse tratamento só poderia ser dado a estudantes indígenas e não a afrodescendentes. Após discussões, votações e deliberações, o procedimento foi estendido à aluna negra, que passou por uma seleção baseada naquela aplicada aos alunos estrangeiros do terceiro mundo que concorrem a vagas e bolsas pelo Programa de Estudantes-Convênio de Pós-Graduação (PEC-PC), do governo federal. Não podemos deixar de observar que tanto a estudante negra, Maria da Consolação Lucinda, quanto o estudante indígena, Tonico Benites, concluíram com brilho seus doutorados, sendo que Tonico, que também participou do seminário no qual este texto foi apresentado, se tornou o primeiro indígena formado doutor em antropologia social pelo PPCAS do Museu Nacional.

O coletivo de mestrandos e doutorandos do PPCAS que se formou a partir dos episódios mencionados considerou que as formas de ingresso já existentes, que não envolviam a tradicional seleção com prova escrita e entrevista presencial, já configuravam uma espécie de ação afirmativa efetuada pelo Programa, e que poderia ter como efeito ampliar a diversidade do corpo discente. A limitação do PEC-PG a estrangeiros e o caráter apenas pontual das outras ações permitindo a avaliação por dossiê' estimularam o coletivo a elaborar uma proposta de política de acesso afirmativo, a ser submetida ao colegiado do PPCAS, de modo a efetivar o ingresso contínuo de negros e indígenas no Programa. Para tanto, foram realizadas inúmeras reuniões presenciais e debates pela internet por meio de uma lista de e-mails que chegou a contar com mais de 400 mensagens.
1 Trata-se de uma modalidade de avaliação pensada para levar em conta de modo adequado as inúmeras especificidades dos candidatos que não poderiam ser devidamente consideradas numa única prova escrita. O dossiê costuma envolver um memorial relatando histórico de vida e intenções de estudo na pós-graduação, bem como qualquer documentação adicional considerada pertinente para indicar a conexão do candidato à sua comunidade. 
O coletivo se organizou sempre de modo horizontal, sem lideranças ou funções pré-determinadas, ainda que tenha muitas vezes se dividido em equipes em constante transformação para realização de determinadas atividades fossem elas o levantamento de dados, o investimento bibliográfico, a redação da proposta ou a comunicação do conjunto com acadêmicos e movimentos sociais interessados na discussão. As principais motivações para sua atuação foram a ausência quase total de ações afirmativas em cursos de pós-graduação no país, a autonomia universitária - em especial das pós-graduações no que tange a seus mecanismos de seleção, garantindo o amparo legal para a elaboração de um processo seletivo que contasse com ações afirmativas - , bem como a existência de um critério de distribuição de bolsas que permitisse descolar adequadamente o denominador étnico-racial das barreiras socioeconômicas. Para isso, já se contava com a existência de um critério socioeconômico para distribuição de bolsas vigente no PPCAS há algum tempo, ele mesmo originário de uma iniciativa que também partiu do corpo discente do Programa.

Com o objetivo de formular uma proposta concreta de ação afirmativa para indígenas e negros no mestrado e no doutorado do PPGAS do Museu Nacional, o coletivo de alunos acabou produzindo uma série de dados que permitiram destrinchar a composição étnico-racial das últimas turmas que haviam ingressado no Programa. Aliadas a depoimentos de candidatos reprovados e experiências pessoais, essas informações permitiram operar uma inversão da questão da ausência de alunos negros e indígenas. Em vez de presumir que eles não se candidatavam ou que não eram aprovados por inabilidade pessoal, passou-se a indagar o que seria possível fazer, de um ponto de vista pragmático imediato, para que houvesse mais candidaturas de indígenas e negros e para que uma quantidade mais significativa delas fosse efetivamente aprovada? Por mais que as respostas sugeridas tenham sido diferentes para cada segmento étnico-racial, sempre foi reivindicação do coletivo gerar uma proposta conjugada que respeitasse as respectivas especificidades e que se apoiasse naquelas que fortaleciam e complementavam umas às outras.

No caso dos indígenas, considerou-se que o próprio processo seletivo, com base sobretudo em uma prova escrita eliminatória, feita em português, mostrava-se inadequado para apreender as realidades dos possíveis candidatos. $O$ formato proposto foi a elaboração de uma carta pessoal em formato de dossiê, o que, sem dúvida, constitui uma base muito mais sólida para uma avaliação que leve em conta de forma mais adequada as múltiplas realidades étnico-políticas dos povos indígenas no Brasil.

Se a simples existência de uma política de ação afirmativa já deveria servir de estímulo a um maior número de candidatos negros e indígenas, sua aprovação nem por isso era garantida. Para o caso dos candidatos negros, que conti- 
nuariam submetidos às diversas etapas da prova tradicional, procedeu-se a um cuidadoso escrutínio de um processo seletivo que, como todos, só é objetivo parcial e aparentemente. Essa análise evidenciou dois modelos de reprovação - excludentes entre si, mas passíveis de atualização a cada ano de acordo com o processo de correção das provas - que atingiam indiscriminadamente todo e qualquer pretendente a uma vaga no PPCAS. Ou o corte se dava em função da pontuação dos candidatos ser insuficiente para o preenchimento das vagas (caso no qual restavam vagas ociosas), ou as vagas eram todas preenchidas e o corte se estabelecia em função dessa limitação (caso em que sobravam candidatos com nota de aprovação mas que em função de sua colocação não eram selecionados - como costuma acontecer com grande frequência nos exames vestibulares na graduação em função do reduzido alcance da educação superior pública). Para superar essas barreiras, o coletivo sugeriu a criação de dois mecanismos interligados e com objetivos precisos: a aprovação afirmativa e o adicional de vagas.

O adicional de vagas seria um indicativo de um esforço suplementar da parte do Programa para adotar ações afirmativas e diversificar seu corpo discente. Diferentemente de um modelo de cotas no qual uma parte das vagas disponíveis é removida da concorrência geral, o adicional de vagas se baseia numa porcentagem das vagas oferecidas ano a ano em cada nível da pós-graduação e varia de acordo com esse número, sem jamais reduzi-lo (na proposta inicial $25 \%$, número conservador escolhido meramente para facilitar a aprovação da proposta). A concorrência ao adicional de vagas ficaria restrita a candidatos negros que fizessem parte da política afirmativa. Já a aprovação afirmativa significaria que candidatos negros em quantidade igual ao adicional de vagas disponível não seriam reprovados por notas inferiores a 7,0 no processo seletivo, fazendo com que necessariamente os melhores candidatos avançassem a cada fase e o adicional de vagas fosse sempre preenchido.

Em conjunto, os mecanismos do adicional de vagas e da aprovação afirmativa permitem que seja mantido um processo unificado de seleção, ao contrário do que ocorre na maior parte dos sistemas de cotas já que os candidatos cotistas disputam as vagas somente entre si em vez de disputá-las também com os candidatos da concorrência geral. A vinculação dos mecanismos permitia que a política de ação afirmativa inicialmente proposta pelo coletivo funcionasse como um piso e não como um teto, já que candidatos negros que obtivessem uma nota acima da nota de corte (como efetivamente veio a acontecer em alguns casos) - e que, portanto, seriam aprovados independentemente da política de acesso afirmativo - não contariam no adicional de vagas. Além disso, essa distribuição serviria para informar sobre o sucesso e a vigência adequados da política: se as vagas adicionais fossem ano a ano não somente preenchidas como o 
piso fosse sistematicamente superado, este poderia ser um sinal de que o acesso afirmativo poderia ser gradativamente reduzido até não ser mais necessário já que toda política afirmativa se prevê necessariamente como temporária.

Tanto para os candidatos indígenas como para os candidatos negros, a proposta do coletivo de alunos considerou a autodeclaração como princípio suficiente de identificação para participação na política de acesso afirmativo. Essa opção foi feita por motivos diversos e específicos à realidade do PPCAS, o principal deles sendo o respeito à autodeterminação que costuma ser um dos pilares da própria antropologia. Além disso, considerou-se que não era preciso nenhuma instância de confirmação da autoidentificação para coibir fraudes em função do universo reduzido de candidatos e também por haver etapas eliminatórias do processo seletivo realizadas de modo necessariamente presencial. Estas formas permitem também a existência de candidatos indígenas e negros que se identifiquem enquanto tais, mas que por qualquer motivo não desejem se inscrever pelo acesso afirmativo. Sugeriu-se assim designar os candidatos que decidam participar dessa ação afirmativa de "optantes".

Destaque-se aqui que a proposta elaborada pelo coletivo dedicou-se exclusivamente ao acesso à pós-graduação, por mais que nas discussões e no preparo da política também tenham sido levadas em conta as questões da permanência no curso e do chamado retorno para a comunidade. Parte da questão da permanência, imaginava-se, seria resolvida justamente com o já mencionado critério socioeconômico para a distribuição de bolsas. Já em relação ao retorno, considerou-se que ele possui um duplo sentido, tanto o de uma devolução e multiplicação da formação e experiências junto a seus contextos de origem, quanto o da efetivação de uma ação transformadora que possa modificar a universidade a partir de dentro. Se é comum e pertinente o argumento de que não basta a simples inserção de alunos negros e indígenas no mundo acadêmico, como se fosse o caso de formatá-los segundo a mesma lógica branca e elitista que sempre reinou na universidade e serviu como ferramenta de exclusão, tampouco é o caso de afirmar que é impossível acolhê-los antes de uma revolução educacional integral, que nunca se sabe quando exatamente a tornará pronta a aceitar a diferença. Tal cenário implicaria que essa transformação partiria antes de tudo de cima, em vez de considerar que ela talvez só possa ser realizada efetivamente numa relação de igualdade com seus interessados mais diretos em todos os níveis da academia.

A primeira proposta elaborada pelo coletivo de alunos foi finalizada e apresentada à coordenação do PPGAS do Museu Nacional em 2007. Para isso, foi fundamental a mediação da representação estudantil, que foi também fortalecida e reestruturada por ocasião dessa discussão, reivindicando um número maior de cadeiras com direito a voto, que até então não tinham sido ocupadas. 
Quase metade do total de alunos então matriculados no mestrado e no doutorado subscreveram a proposta, num exemplo de movimentação estudantil sem precedentes na história do Programa. Ficou também claro que se tratava de uma proposta que não se conectava especificamente a nenhuma orientação teórica ou linha de pesquisa da instituição, já que entre os alunos que defenderam a proposta havia orientandos de praticamente todos os professores da casa.

Apesar de ter sido inicialmente apreciada nesse mesmo ano de 2007, não foi possível encaminhar a matéria para deliberação. Segundo o corpo docente, era preciso, primeiro, amadurecer a proposta, o que punha em jogo outra característica importante do coletivo responsável pela sua elaboração: o fato de se tratar de um movimento estudantil ampliaria a tendência de condená-la ao ocaso, já que as composições das turmas se alteram a cada ano, não só com ingressantes e concluintes como com viagens para o campo e reclusões para a redação de dissertações e teses. Desse fator limitador, ao menos duas constatações se destacam. A primeira foi a contínua reativação do movimento, sempre a pedido de alunos novos que demonstravam interesse em levar adiante a discussão, 0 que sedimentou sua força enquanto demanda de boa parte do corpo discente. A segunda foi a importância dos estudantes não deixarem de lado suas demais atribuições acadêmicas com trabalhos que na maior parte das vezes não tinham nenhuma conexão direta com o tema das ações afirmativas.

A fim de "amadurecer a proposta", foram realizadas reuniões individuais de diferentes membros do coletivo de alunos com cada um dos professores do PPCAS, sob condição de "anonimato". Ou seja, fez-se um acordo para que as posições e os argumentos mobilizados nesse momento não fossem vinculados a quem os declarou. Somado ao fato de que em geral os grupos que consultaram cada professor incluíam seus próprios orientandos, isso permitiu que os docentes apresentassem suas predileções e suas reservas de modo surpreendentemente franco, o que ajudou o coletivo estudantil a encaminhar melhor as possíveis modificações necessárias à a provação da proposta.

Mesmo muitos dos professores que disseram ser favoráveis à iniciativa frisaram a importância de se encaminhar a questão de forma lenta e sempre muito cuidadosa, de modo a evitar cisões no colegiado. Nesse sentido, o coletivo estudantil foi alertado para que não apresentasse a questão nos termos de um embate progressista contra professores com posições mais "conservadoras", já que grande parte dos docentes tinha um histórico de reconhecida atuação política em defesa de questões sociais as mais diversas.

Vários professores foram contrários ao mecanismo de aprovação afirmativa porque ele removeria parcialmente a possibilidade de reprovar candidatos, algo que era feito não só mediante o ajuste comparativo das notas durante o processo seletivo, como de maneira mais peremptória nos raros casos em que um 
aluno, apesar do bom rendimento em determinada etapa do processo seletivo, revelasse nas seguintes não ter o perfil esperado de um aluno do PPCAS do Museu Nacional. Ao mesmo tempo, afirmava-se que era preciso investir em medidas que diminuíssem a chamada "barreira simbólica" que pairaria sobre a instituição e que muitas vezes desestimulava candidaturas mais diversas, propondo a criação de um curso preparatório para potenciais interessados.

A principal questão para uma parte significativa do corpo docente mais resistente à implementação de ações afirmativas de recorte étnico-racial era a da reificação de uma realidade considerada muito mais fluida que as divisões binárias permitiriam apreender, já que a política corria o risco de gerar efeitos imprevistos. Chegou-se a comentar que a inclusão de alunos negros no Programa poderia criar conflitos raciais que jamais existiram naquele espaço, bem como falou-se sobre o risco de se realizar uma inclusão nominal que servisse a um acolhimento da diferença meramente retórico.

Talvez o que o coletivo mais tenha escutado nas conversas com os professores é que era preciso reunir mais dados, solidificar ainda mais a proposta, ouvir mais vozes a respeito do tema e só encaminhar novamente a discussão quando o momento fosse mais adequado. Diante dessa avaliação, diferentes coordenações do PPCAS incentivaram a realização de eventos e discussões que mantivessem o debate em torno das ações afirmativas. O Programa recebeu, assim, acadêmicos especialistas no tema, bem como promoveu um encontro com estudantes indígenas que cursavam a graduação na Universidade Federal de Minas Cerais.

Em 2008, foi reeditada a lei 10.639, de 2003 - que inicialmente incluíra como obrigatório o ensino de história e cultura afro-brasileira nas escolas como lei 11.645, que acrescentava a dimensão indígena. Em 2010, ocorreu, no Supremo Tribunal Federal, a audiência pública sobre a legalidade das ações afirmativas no Ensino Superior em função de ações contrárias a políticas de cotas. As transcrições das falas dos participantes, incluindo acadêmicos, líderes de movimentos sociais e juristas, constituem valioso instrumento para quem deseja se aprofundar no tema (Vários Autores, 2010). Finalmente, em 2012, procedeu-se ao julgamento de ambas as ações no STF, que, numa decisão unânime, sepultou de vez qualquer dúvida a respeito da constitucionalidade das ações afirmativas com recorte étnico-racial, contrariando palpites constitucionalistas emitidos por muitos cientistas sociais. O voto do relator (Lewandowski, 2012) é não somente uma peça acadêmica em si bastante acessível, como teve seu texto informado pelos posicionamentos de diversos estudiosos do tema, e merece ser consultado.

Nesse mesmo ano, ou seja, nada menos que seis anos após o início do movimento e cinco após a primeira apresentação da proposta do coletivo de alunos, 
esta encontrou um ambiente fértil para ser finalmente apresentada ao colegiado do PPCAS, tendo sido aprovada, na votação que se seguiu ao intenso debate, por 11 votos a 1, com duas abstenções. Entretanto, três modificações foram introduzidas com a finalidade de facilitar a aprovação da proposta: a fixação de um número de vagas para os optantes indígenas (mais recentemente substituída por uma adicional de $10 \%$ das vagas abertas); a diminuição do percentual de vagas para optantes negros de $25 \%$ para $20 \%$ do total; e o abandono do mecanismo da aprovação afirmativa para os candidatos optantes negros, substituído por uma diminuição da nota de corte em todas as fases do processo seletivo de 7,0 para 5,0.

Como o coletivo havia previsto, essa alteração reduziu a eficácia da política de acesso afirmativo, uma vez que provocou uma modificação na média e na moda históricas das notas atribuídas às provas escritas. Tradicionalmente, estas tendiam a se concentrar entre 5,0 e 6,9; agora, observa-se uma tendência para que fiquem abaixo de 5,0. Além disso, nos três anos de aplicação do sistema até então, em dois deles, no doutorado, não houve a aprovação de nenhum optante negro no adicional de vagas - ainda que tenha ocorrido ingresso de optantes com notas acima de 7,0.

De todo modo, e como não poderia deixar de ser, a implementação da política de ação afirmativa do PPCAS do Museu Nacional repercutiu muito. A então Pró-Reitora de Pós-Graduação e Pesquisa da UFRJ enviou uma mensagem de congratulações pela iniciativa pioneira; os professores das demais pós-graduações do Museu Nacional não colocaram nenhum obstáculo ao edital de seleção que incluía as cotas; a Seppir divulgou a novidade em seu site; e assim por diante. Além disso, a partir desse momento, muitas outras pós-graduações, em muitos casos pressionadas pelos estudantes (como a própria Associação de Alunos da Pós-Graduação da UFRJ), deram início à discussão sobre a implantação de sistemas semelhantes: Ippur, UnB (Sociologia e Antropologia), Unicamp, USP, UFMG, UFSC, UFSCar, UFRCS... Em quase todos os casos, o modelo do PPCAS do Museu Nacional serviu de base para as discussões e, muitas vezes, para a própria proposta. Além disso, membros do coletivo que elaborou a proposta foram chamados para participar dos debates para a implantação dos sistemas. Em todos os casos já aprovados ressalta um fato muito interessante: nas votações públicas, as a provações sempre se deram por larguíssima margem de votos. Esse dado comprova a importância e a eficácia da luta e da pressão política em favor dessas iniciativas.

Nesse sentido, do muito que o coletivo aprendeu ao longo do processo de elaboração da política de acesso afirmativo, provavelmente a lição mais útil a transmitir para iniciativas similares é a de que existe uma série de impedimentos que são continuamente colocados para a discussão e para a própria deliberação da ação afirmativa. Se esses obstáculos exigem um trabalho contínuo, e 
muitas vezes prévio, para serem adequadamente enfrentados, grande parte deles pode ter por efeito muito concreto o bloqueio intransigente de qualquer ação verdadeiramente transformadora da situação. Um ponto de vista pragmático em relação aos objetivos, que são de fato bastante modestos diante da dimensão do problema, permite obviar o labirinto da discussão eterna de princípios que muitas vezes acaba por cercear o debate e drenar os participantes de sua potência de mobilização. E se os efeitos das ações afirmativas na pós-graduação parecem, por um lado, bastante moderados - trata-se, afinal, de umas poucas pessoas a cada ano - , por outro lado, sabe-se perfeitamente que seu potencial multiplicador e inovador pode ser absolutamente radical.

Cumpre lembrar, ainda, que a melhor forma de compreender as ações afirmativas não é como uma concessão do Estado, mas como algo que ele foi forçado a reconhecer como uma obrigação diante das demandas e lutas dos movimentos sociais minoritários. Desse modo, não se trata tanto de caracterizar os alunos que ingressam por meio dessas ações como meros beneficiários de políticas públicas, mas como agentes ativos na reivindicação de espaços que por muito tempo Ihes foram negados. Isso significa também, de modo ainda mais importante, que a própria efetivação das ações afirmativas constitui antes de tudo um reconhecimento do gigantesco mérito das lutas que vêm sendo travadas há muitos e muitos anos por negros e indígenas no país, cujo verdadeiro protagonismo jamais deve ser minimizado.

Costaríamos de concluir essas já longas observações evocando a célebre e terrível fórmula de Primo Levi (2004) a respeito do nazismo: "a vergonha de ser um homem". Vergonha, lembremos, que se opõe à culpa, caminho que só conduz ao suposto direito arrogante de distinguir culpados e inocentes, ou ao duplo absurdo de afirmar que todos ou ninguém são culpados. A vergonha, observou Deleuze, tem a ver com o fato de que somos inevitavelmente manchados por algo como o nazismo e o racismo. Em primeiro lugar, pelo simples fato de existirem seres humanos e estruturas sociais racistas; mas também porque sentimos confusamente que não somos capazes de impedir sua existência e que, às vezes, chegamos mesmo a fazer concessões a ele. Nós acreditamos que resistir a essa tentação e remar contra a corrente é um dever.

Marcio Goldman é Professor Titular do Programa de Pós-Graduação em Antropologia Social (Museu Nacional/UFRJ).

Gabriel Banaggia é pós-doutorando do Programa de Pós-Graduação em Antropologia Social (Museu Nacional/UFRJ). 


\section{REFERÊNCIAS BIBLIOCRÁFICAS}

\section{AIDOO, Ama Ata}

1977 Our Sister Killjoy: Or, Reflections from a Black-Eyed Squint. Londres, Longman.

CARVALHO, José Jorge de e SECATO, Rita Laura

2002 "Uma proposta de cotas para estudantes negros na Universidade de Brasília". Série antropologia, 314. Brasília, Universidade de Brasília.

CARVALHO, José Jorge de

2006 Inclusão étnica e racial no Brasil: a questão das cotas no

Ensino Superior. São Paulo, Attar Editorial.

DELEUZE, Gilles

1990 [1985] “Les Intercesseurs". In Pourparlers 1972-1990. Paris, Minuit, p. 165-184.

FERES JR., João

2004 "Ação afirmativa no Brasil: fundamentos e críticas". Econômica, 6 (2): 291-312.

FERES JR., João e DAFLON, Verônica Toste

2007 "Ação afirmativa em perspectiva internacional: estudos e casos". In FERES JR., João; POMBO DE OLIVEIRA, Marina; e DAFLON, Verônica Toste (orgs.). Guia bibliográfico multidisciplinar: Ação Afirmativa:

Brasil, África do Sul, Índia, EUA. Rio de Janeiro, DP\&A, p. 9-27.

GOLDMAN, Marcio

2006 Como funciona a democracia. Uma teoria etnográfica da política. Rio de Janeiro, Editora 7 Letras.

LEVI, Primo

2004 Os afogados e os sobreviventes. São Paulo, Paz e Terra.

LEWANDOWSKI, Ricardo

2012 Arguição de descumprimento de preceito fundamental 186. Disponível em http://www.stf.jus.br/arquivo/cms/noticiaNoticiaStf/ anexo/ADPF186RL.pdf. Acesso em 24/01/2017. 
NEEDHAM, Rodney

1972 Belief, Language and Experience. Oxford, Basil Blackwell.

PENA, Sérgio

2007 "Ciências, bruxas e raças". In FRY, Peter; MACGIE, Yvonne; MAIO, Marcos Chor; MONTEIRO, Simone; e SANTOS, Ricardo Ventura (orgs.). Divisões perigosas: políticas raciais no Brasil contemporâneo. Rio de Janeiro, Civilização Brasileira.

PIGNARRE, Philippe e STENGERS, Isabelle

2005 La Sorcellerie capitaliste: Pratiques de désenvoûtement. Paris, La Découverte.

SILVÉRIO, Valter Roberto

2002 "Ação afirmativa e o combate ao racismo institucional no Brasil". Cadernos de Pesquisa, 117: 219-246.

VALENTE, Ana Lúcia E. F.

2006 'Má vontade antropológica' e as cotas para negros nas universidades (ou usos e abusos da antropologia na pesquisa educacional II: quando os antropólogos desaprendem". InterMeio, 12 (24): 84-103.

VÁRIOS AUTORES

2005 Horizontes Antropológicos, 11 (23), jan/jun.

VÁRIOS AUTORES

2010 Audiência pública sobre a constitucionalidade de políticas de ação afirmativa de acesso ao Ensino Superior. Disponível em http://www.stf.jus.br/portal/ cms/verTexto.asp?servico=processoAudienciaPublicaAcaoAfirmativa. Acesso em 24/01/2017. 


\section{ABSTRACT}

The first part of this text reflects on racism and inclusion from the point of view of our formation as anthropologists and our experience as ethnographers who believe that the effects of fieldwork and ethnography must surpass the theoretical or academic field, since there is always something to learn from the people with whom we work. After that we give an account of the long process of implementation of ethnic-racial quotas in the Postgraduate Program in Social Anthropology-National Museum. In addition to its intrinsic importance, we believe that this record can be useful for the growing number of initiatives aimed at the implementation of affirmative action policies in several postgraduate programs. At the same time, we will not shy away from some initial assessments of the workings and directions that the process has taken in the National Museum, and we also propose a few connections between this experiment and the reflections of the first part of the text.

Recebido em 30.10.2016. Aceito em 16.03.2017.

\section{KEYWORDS}

Affirmative action, Inclusion, Racism, Postgraduate education, Social anthropology. 